\title{
MEDIA CULTURE
}

DOI : https://doi.org/10.33739/2587-5434-2020-3-39-48

\section{LIBRARY BLOGODIDACTICS}

\author{
Anna Onkovych \\ Doctor of Pedagogical Sciences, Professor \\ Kyiv Medical University \\ (Kyiv, Ukraine) \\ email: onkan@ukr.net \\ Viktoria Agarkova \\ Nikolaev Regional Universal Scientific Library \\ (Mykolaiv, Ukraine) \\ Marina Bogolyubova \\ Senior Lecturer \\ Kiev Medical University \\ (Kyiv, Ukraine) \\ email: m.boholiubova@kmu.edu.ua
}

\begin{abstract}
Abstract. Nowadays, information technologies have become widespread and diverse as they reflect the processes of searching, analyzing and realizing different information. Social networks are a source of development and self-development of a person's professional competence. Professional-oriented authors' pages are a way to improve professional self-education. Thematic pages have become platforms for sharing best practices of specialists in different fields of knowledge. The terms "information literacy", "media and information literacy" refer to a new terminology system that is actively being enriched. The concept of media didactics - the use of media for educational purposes - is relatively new and today unites technologies (techniques) of various components. For example, press didactics-прессодидактика and press linguistics прессолингвистика, radio didactics-радиодидактика, tele-didactics-теледидактика, film didacticsкинодидактика were focused on the use of "old" media for educational purposes. With the advent of information and communication technologies, new media didactic concepts appeared - multimedia, Internet didactics, which quickly became "umbrella". Media teachers have successfully developed new technologies for the use of media in the process of education and training. Innovative forms of media work appeared in libraries. Examples of their presence in social networks indicate the validity of updating the concept of "library blogodidactics". In this article it is illustrated with concrete examples . In particular, attention is drawn to new forms of work with the book - bookspalas (flashbook) - didactics, local history location, etc.
\end{abstract}

Keywords: media didactics, media educational technologies, internet didactics, blog didactics. library blog didactics, knyhospalah-didactics, webinar didactics. 


\title{
БИБЛИОТЕЧНАЯ БЛОГОДИДАКТИКА
}

\author{
А. В. Онкович \\ доктор педагогических наук \\ профессор кафедры украинского и латинского языков \\ (Киевский медицинский университет, Украина, Киев) \\ email: onkan@ukr.net \\ В. В. Агаркова \\ Николаевская областная \\ универсальная научная библиотека \\ (Николаев, Украина) \\ М. М. Боголюбова \\ старший преподаватель \\ Киевский медицинский университет \\ (Украина, Киев) \\ e-mail: m.boholiubova@kmu.edu.ua
}

\begin{abstract}
Аннотация. В наше время информационные технологии получили распространение и разнообразие, поскольку отражают процессы поиска, анализа и осознания различных сведений. Социальные сети источник развития и саморазвития профессиональной компетентности личности. Профессиональноориентированные авторские страницы - способ повышения профессионального самообразования. Тематические страницы стали площадками для обмена передовым опытом специалистов в разных отраслях знания. Термины «информационная грамотность», «медиа-информационная грамотность» относятся к новой терминосистеме, которая активно обогащается. Понятие медиадидактика использование медиа в образовательных целях - относительно новое и сегодня объединяет технологии (методики) различных составляющих. Например, прессодидактика и прессолингводидактика, радиодидактика, теледидактика, кинодидактика были ориентированы на использование «старых» медиа в образовательных целях. С появлением информационнокоммуникационных технологий появились новые медиадидактические понятия мультимедиадидактика, Интернет-дидактика, которые достаточно быстро стали «зонтичными». Медиапедагоги успешно разрабатывали новые технологии использования медиа в процессе обучения и воспитания. Появились инновационные формы медиаработы библиотек. Примеры их присутствия в социальных сетях свидетельствуют о правомерности актуализации понятия «библиотечная блогодидактика». В статье это иллюстрируется конкретными примерами. В частности, обращается внимание на новые формы работы с книгой - книгоспалах (флешбук)-дидактика, краеведческая локация и др.
\end{abstract}

Ключевые слова: медиадидактика, медиаобразовательные технологии, интеренет-дидактика, блогодидактика. библиотечная блогодидактика, книгоспалах-дидактика, вебинародидактика

\section{ВВЕДЕНИЕ}

В наше время информационные технологии получили распространение и разнообразие, поскольку отражают процессы поиска, анализа и осознания различных сведений. Термин «информационная грамотность» относится к новой терминосистеме, его впервые употребил 1974 П. Журковский (Zhurkovskiy 1974). Исследователи отмечают, что другой термин - «информационные технологии» был предложен В. Глушковым в 1987 г. (Glushkov 2020). Впоследствии выделилось понятие 
«информационные технологии обучения», а с развитием средств телекоммуникаций и глобальной сети Интернет получил распространение термин «информационно-коммуникационные технологии обучения〉 (Oncovich 2012) отслеживают и обобщают медиаобразовательные технологии (Onkovich 2012; Paris Declaration on Media and Information Literacy in theDigital Era [Electronic sourse]). Медиадидактика, ориентированная на сферу общения, сейчас вбирает себя часть понятий ИКТтехнологий, которые остаются и в сфере информатики. Компьютерные коммуникации существенно влияют на формирование нового содержания образования, на организационные формы и методы обучения. Понятие «информационно-коммуникационные технологии» должным образом воспроизводит эти процессы. Его используют и специалисты по медиаобразованию, хотя в последние годы получает распространение термин «медиа-информационные технологии». К тому же ЮНЕСКО рекомендует развивать медиа и информационную грамотность одновременно (Onkovich 2018).

\section{ОБЗОР ПУБЛИКАЦИЙ}

Понятие медиадидактика - использование медиа в образовательных целях - относительно новое и сегодня объединяет технологии (методики) различных составляющих. Например, прессодидактика и прессолингводидактика, радиодидактика, теледидактика, кинодидактика были ориентированы на использование «старых» медиа в образовательных целях (Onkovich, А. 2015). С появлением информационно-коммуникационных технологий появились новые медиадидактические понятия мультимедиадидактика, Интернет-дидактика (Onkovych 2020). Вовлечение в учебный процесс «новых» медиа актуализировало понятие «медиа-информационные технологии». И сегодня медиадидактика обогащается новыми составляющими, приобретают популярность новые явления, которые свидетельствуют о развитии интернет-дидактики: викидидактика (использование Википедии в образовательных целях), блогодидактика (использование блогов с этой же целью), вебинародидактика (использование вебинаров) и т. д. Этот процесс обогащения новыми понятиями продолжается. В любом случае медиасредства используются для коммуникации, так как для них определяющее - общение в социуме. И именно как результат анализа опыта украинских педагоговпрактиков появились эти термины. Раскрытию этих новых понятий посвящен ряд публикаций (Onkovich, A., Onkovich, G., Lyalina O. 2020; Onkovich G. Knigospalakh-didaktika). Анализ источников показывает ускоренный темп внедрения медиаобразовательных технологий в учебном процессе высшей школы.

Исследователи рассматривали технологии использования медиасредств в обучении, предлагали авторские методики. Сегодня благодаря им, ученым и педагогам-практикам еще недавно новое понятие «медиадидактика» стало «зонтичным» для технологий, разработанных и внедренных в образовательный процесс. В свою очередь, одно из них, понятие «Интернет-дидактика», - ныне тоже «зонтичное» для новейших терминов, которые возникли благодаря появлению Интернета. Если ранее Интернет-ресурс рассматривался как резерв повышения профессиональной компетентности, то сейчас он уже активно вошел в повседневную практику не только образовательных структур. Социальные сети рассматриваются как источник развития и саморазвития профессиональной компетентности, а профессионально-ориентированные авторские страницы в социальных сетях - как способ повышения профессионального самообразования. Успешно функционируют тематические страницы в Фейсбуке, которые стали площадками для обмена передовым опытом медиадидактов Украины.

\section{ОСНОВНАЯ ЧАСТЬ}

В настоящее время понятие блогодидактика тоже стало «зонтичным» имеет несколько составляющих (перечень открытый): научно-педагогическая; педагогическая; языково- 
педагогическая; инженерная (на примере подготовки специалистов для нефтегазовой сферы) медицинская.

В этой статье мы представляем новое понятие - библиотечная блогодидактика, которое возникло в результате наблюдений за присутствием библиотек в социальных сетях. Перед тем в образовательном пространстве появились такие понятия, как «медицинская блогодидактика», «фармацевтическая блогодидактика», «стоматологическая блогодидактика» - благодаря студентампервокурсникам Киевского медицинского университета, которым было предложено найти и представить товарищам по группе периодические издания по будущей специальности, обратить внимание на профессиональный язык печатных и электронных изданий. Однако многим студентам было интересно «пойти дальше» - в интернет-пространство. Так в поле зрения оказались различные медиа-продукты - сайты, блоги, страницы ...

Эти процессы не обошли и библиотечную сферу, ведь современные библиотеки не стоят в стороне цивилизационных процессов и активно усиливают свое присутствие в информационном пространстве. Это актуализирует и активизирует творческий поиск библиотечных работников. Наблюдение за этими процессами и побудило нас к представлению нового понятия - «библиотечная блогодидактика». Сегодня мы нуждаемся в добавлении к новой терминосистеме профессиональноориентированной блогодидактики этого понятия.

Обратимся к некоторым страницам и сайтам, которые ведут библиотечные работники в социальных сетях. Они, как правило, подобны по структуре. Однако есть несколько «авторских» находок, на которые обратим внимание с целью активизировать творческий поиск библиотек. В частности, представим такое явление, как книгоспалах (флешбук), технологии создания которого выделилась в понятие «книгоспалах-дидактика» (Onkovych 2017). Итак, несколько примеров присутствия областных библиотек в социальных сетях, которые свидетельствуют о правомерности появления понятия «библиотечная блогодидактика» в образовательном пространстве.

Херсонская областная универсальная научная библиотека имени Олеся Гончара (https://lib.kherson.ua/projects.htm) в сети Фейсбук представлена направлениями (https://www.facebook.com/khersonlibrary/), по структуре подобными до аналогичных представлений других библиотечных заведений :

публичная информаџия, историческая справка, библиотека сегодня, Гончар и Херсонщина, фотопроект одной книги, юбилей моей библиотеки, библиотека на страницах печати, об отделах, телефонный справочник, как записаться в библиотеку, график работы и адрес библиотеки, правила пользования, платные услуги, фотопроект «Photo Stream», библиотека - калейдоскоп интересных фактов, видеоматериаль, наши презентации, вестник государственных закупок, заявка на проведение мероприятия, обратная связь.

Ровенская областная универсальная научная библиотека была основана в феврале 1940 года. Книжный фонд состоял из конфискованных книг частных библиотек, библиотеки князей Любомирских, городского музея, польской гимназии, польской библиотеки учителя, уездного отдела молодежной образовательной и полицейской библиотек. На ее сайте в разделе «История» отмечается: Ровенская областная универсальная научная библиотека (официальное название - Коммунальное учреждение "Ровенская областная универсальная научная библиотека" Ровенского областного совета) - один из крупнейших культурных центров края, региональное хранилище произведений печати, областной депозитарий краеведческих изданий, научно-информационное учреждение, доступная для всех слоев населения. Библиотека имеет мощную электронную библиотеку, объем которой составляет 635 тыс. библиографических записей и полных текстов документов. Созданы и поддерживаются 6 сайтов и 2 блога. Для пользователей библиотеки качественно предоставляются 42 
новые услуги через социальные сети Интернет, виртуальные услуги, услуги через Пункты доступа граждан к официальной информации.

Благодаря сайту узнаем: в библиотеке действуют клуб «В мире прекрасного», литературная гостиная «Собеседник», университет «Здоровье нации», ресурсный центр «Окно в Америку», Информационно-ресурсный центр для преподавателей английского языка, проект «Заочный абонемент〉 немецкого культурного центра Гете-Институт в Киеве, Учебно-тренинговый центр, центр «Интернет-очки» для слабовидящих, центр европейской информации Комната семейного чтения структурного подразделения абонемента. К услугам пользователей библиотеки бесплатный Интернет, электронная почта, ксерокс, комфортные читальные залы и абонемент со свободным доступом к книгам, просторные актовые залы и холлы, летняя читальня. Проводятся различные мастер-классы. Инвалидам и пожилым людям бесплатно предоставляется услуга «Книга домой».

Остановимся на нескольких сообщениях, которые отражают медиаопыт Николаевской областной универсальной научной библиотеки, основанной в 1881 г. Благодаря современным информационным технологиям, мы можем получить интересную информацию. На сегодня - это ведущий просветительский и культурный центр Николаевской области, депозитарий краеведческих изданий, крупнейшее книгохранилище произведений печати на юге Украины, книг, периодических изданий, аудиовизуальных и изобразительных материалов, карт, нот, патентов и других документов по всем отраслям знаний на 44 языках мира. К услугам пользователей 6 специализированных читальных залов, Центр электронных средств информации и Интернет-центр.

Направления работы Николаевской областной универсальной научной библиотеки: - участие в формировании региональной библиотечной политики, научно-методическое руководство библиотеками области; - организация работы коллегиальных органов управления библиотечным делом области: объединенного научно-методического Совета областных библиотек для взрослых, детей и юношества при управлении культуры, национальностей и религий облгосадминистрации; обеспечение свободного доступа к информации через фонды библиотеки и глобальную сеть Интернет, организация библиотечно-библиографического и информационного обслуживания; научно-исследовательская деятельность по изучению документов XVII-XXI вв., в том числе краеведческого направления; техническое и методическое обеспечение функционирования региональной библиотечной компьютерной сети, построенного корпоративного каталога библиотек; введение новейших компьютерных технологий в практику работы библиотек области; осуществление культурно-просветительской, образовательной и издательской деятельности; реализация информационно-библиотечных проектов и программ; - изучение и распространение инновационного опыта работы библиотек, организация непрерывного профессионального образования библиотечных кадров области; - взаимодействие с региональными, всеукраинскими, международными организациями и фондами в области библиотечного дела.

Библиотека является местом проведения международных, всеукраинских научнопрактических конференций, базой для обмена инновациями с коллегами из других библиотек. В то же время работники библиотеки представляют свое учреждение для проведения профессиональных мероприятий различных уровней: всемирных конгрессов ИФЛА (Германия, Бразилия, Аргентина) и Библиотечной Ассамблеи Евразии (Россия), международных семинаров и стажировок (США, Бельгия, Австрия, Польша), ежегодных международных конференций, приобретая новый опыт для дальнейшего его внедрения в практику своей работы. (Mikolaïvska oblasna universalna naukova biblioteka). Для распространения актуальной информации сотрудники используют современные формы распространения знаний, в частности, через вебинары. Например, Вебинар «Социальные сети как инструмент имиджевого позиционирования библиотек» состоялся 8 октября 2020 г. на платформе Zoom в рамках вебкоучингу «БиблиоSTUDIES» для библиотечных работников области. В частности, 
были представлены лучшие примеры использования социальных сетей библиотеками мира и наиболее употребительные сети мультиформатного контента. Сотрудники библиотеки также участвуют в онлайн-встречах по вопросам работы экспертов и механизма оценки книг, рассматривают также вопросы об особенностях работы в персональном кабинете Эксперта «Автоматизированной системы отбора и распределения книжной продукции».

В начале октября в Информационно-ресурсном центре международного партнерства состоялось очередное заседание английского книжного клуба с участием волонтера Брэда Баннистера, онлайн-встреча с ученицей Николаевской общеобразовательной школы №19, участницей Программы для будущих лидеров (FLEX) и амбасадоркою EducationUSA Ukraine Златой Колесник. Гостья рассказала о проект "Лидерство для девушек", который был реализован совместно с центром "Окно в Америку".

А теперь - о некоторых творческих авторских проектах, инициированных библиотечным работником г. Днипро Т.И. Глобою. «Флешбук» (книгоспалах) - это инновационная форма библиотечной работы, направленная на активное популяризацию книг в социальных сетях. Эта "книга флешмоба" появилась в Интернете сравнительно недавно и одновременно в разных социальных сетях. В исследовании Т.И. Глобы (Onkovych 2017; Globa 2018). отмечается, что инициаторы предложили создать "FanPage" на имя определенной книги и пригласить на нее своих друзей. Идею подхватили библиотечные работники в разных странах. Так, в Украине ко Дню украинской грамотности и языка 9 ноября 2017 г. Днепровская центральная городская библиотека начала использовать эту форму продвижения книг. Первый флешбук назвали "Словарь Бориса Гринченко", поскольку четыре тома "Словаря ...» являются вершиной украинской лексикографии XIX - первой половины XX века. Немало материалов, касающихся Словаря, представлено на флешбукстранице, ведь его источником служили этнографические и фольклорные записи, заметки повседневной жизни, сообщения о традиционных ремеслах, традициях и культурных достижениях украинского народа. Работа Бориса Гринченко выходила в 1907 - 1909 гг. Словарь - научное достижение тогдашней лексикографии, итог работы нескольких поколений украинских языковедов. На странице флешбука - все материалы из экспозиции мемориального музея Гринченко. Представлены также различные виды словарей, переводческие, интерпретационные, орфографические, фразеологические, этимологические, топонимические словари, синонимов паронимов, антонимов; иллюстрации некоторых толкований отдельных слов материалы Мемориального Музея села Гринченко (с. Алексеевка, Перевальский район, Луганская область), документальный фильм «Борис Гринченко. Ловец слов ", фотоинформация.

Иной пример флешбука, созданного в этой же библиотеке - «Флешбук "Легенди про козаків" Еліни Заржицької». На этой «странице» можно найти отрывки из «Легенд ...», которые сопровождаются иллюстрациями, креативными произведениями молодежи, цитатами на темы, народными поговорками и пословицами, аудио - и видеоматериалами. Постепенно наполняемая страница стала мини энциклопедией о казачестве, Днепропетровщине.

Флешбук-книгоспалах «"Легенди про козаків" Еліни Заржицької» (https://www.facebook.com/ 97-390387901318673 /) начинался популярным в то время козацьким маршем группы «Тень солнца», что приподнимло настроение участникам мероприятия. Далее шел рассказ, как над книгами работала художник-иллюстратор Елена Железняк, которая сумела своими рисунками очень удачно подчеркнуть индивидуальные черты каждого персонажа.

Элина Заржицкая на страницах своих книг не только знакомит юных читателей с лексическим значением незнакомых для них слов, расширяет их словарный запас, но и развивает их художественный вкус. Флешбук-книгоспалах дополнялся (и дополняется) значениями и красочными 
иллюстрациями новых слов, песнями, буктрейлерами о сказочных героях. Авторские иллюстрации чередуются с изображениями художественных полотен о казачьих временах, интересными материалами о народном быте со ссылками на интернет-ресурсы, мультфильмы. На страницах представлены песни, фрагменты текстов, цитаты героев. Виртуальное общение с читателями легенд про казачий край в рамках флешбук-книгоспалаха завершалось творческой встречей Элины Заржицкой с учениками.

На этой странице материалы подобраны таким образом, что у любознательных учеников возникало желание прочитать эти книги, больше узнать об истории и народных обычаях края и города Днипро; не навязчиво, но очень эффективно популяризовалось многогранное творчество Э. Заржицкой в социальной сети, поскольку флешбук-книгоспалах объединил на своей странице все публикации и видеотворчество писательницы в то время.

В социальных сетях, благодаря медиаобразовательным технллогиям, возникли инновационные формы работы библиотек г. Днипро - книгоспалахи-флешбуки и краеведческая локация «ДнипроКультура». Активная популяризация книги сочетается с видео, мультимедийными презентациями, буктрейлерами, ссылками на сайты об истории, культуре и искусстве Приднепровья.

С начала 2017 сотрудники Днепропетровской областной универсальной научной библиотеки имени Первоучителей славянских Кирилла и Мефодия создали Портал «ДнипроКультура» (https://www.dnipro.libr.dp.ua) - просветительский проект, посвященный культуре Приднепровья в целом и современной Днепропетровской области в частности. На Портале размещаются оригинальные авторские статьи об интересных культурно-художественных событиях края, о выдающихся деятелях творческих профессий, публикуются также зарисовки и очерки про историю городов и сел Днепропетровщины, рассказы о памятниках культуры и памятниках природы, про театры, музеи, библиотеки. Как отмечает инициатор создания Портала Т. Глоба (Globa 2018), его пользователи имеют возможность просмотреть фотографии достопримечательностей, архитектуры, портреты выдающихся деятелей, фотографии изделий мастеров народных промыслов, почитать произведения местных авторов, ознакомиться с мультимедийными ресурсами культурного наследия Днепропетровской области. В отличие от флешбуков-книгоспалахов, как временных акций, к страницам Локации учителя, библиотечные работники, краеведы, представители творческих профессий присоединяются без ограничения времени, поскольку Краеведческая локация «ДиипроКультура" не ограничена временными рамками. Как и сам Портал, Локация наполняется просветительскими материалами не только профессиональных краеведов, историков, но и работников 16 отделов Днепропетровской областной научной универсальной библиотеки и крупнейших библиотечных учреждений Днепропетровской области. Уникальные коллекции края, найденные и распространяемые библиотеками, становятся общим достоянием. Информация о малоизвестных талантливых представителях региона, их творчество, увлечения собираются на «ДнипроКультуре» стараниями авторского коллектива. Просветительский проект «ДнипроКультура» имеет ресурс для своего развития - краеведческую локацию в социальных сетях.

В социальной сети есть несколько страниц, направленных на продвижение книг. Они представлены на сводной странице «Книгоспалах-дидактика» [https://www.facebook.com/groups/1255700747839235/].

\section{Выводы}

Социальные сети рассматриваются нами как источник развития и саморазвития профессиональной компетентности, а профессионально-ориентированные авторские страницы в социальной сети - как способ повышения профессионального самообразования. Успешно функционируют тематические страницы в Фейсбуке, ставшие площадками для обмена передовым 
опытом медиадидактов Украины. Примеры присутствия областных библиотек в социальных сетях свидетельствуют о правомерности появления понятия «библиотечная блогодидактика» в образовательном пространстве.

\section{LIST OF REFERENCES}

Biletsky Volodymyr, Onkovych Anna \& Yanyshyn Olha (2019) MEDIA EDUCATION TECHNOLOGIES IN DEVELOPING STUDENTS' PROFESSIONAL COMPETENCE // International ScientificPedagogical Organization of Philologists "WEST-EAST " (ISPOP). Scientific Journal "WEST-EAST" Vol. 212, N1 (October, 2019), p.p. 110-114. https://doi.org/10.33739/2587-5434-2019-2-2-110-114

Zhurkovskiy, P. (1974). (Zurkowski P. G. The Information Service Environment Relationships and Priorities [Electronic resourse]: Related Paper 5 / Paul G. Zurkowski // ERIC. - 1974. - Mode of access : http://eric.ed.gov/?id=ED100391).

Glushkov, V. (1997). Osnovy bezbumazhnoy informatiki. M.: Nauka. 1987.-552 s. Sultanova L.Yu.. Krinitsya G.V. (2000) Aktualnist doslidzhpennnya informatsiyno-komunikayltsiynikh tekhnologiy v osvitnomu protsesi // Neperevna pedagogichna osvita KhKhI stolittya: zb. Materialiv KhUII Mizhnarodnikh pedagogichno-mistetskikh chitan pam»yati prof.O.P.Rudnitskoï .- Vip № (15). K.: Talkom. 2020. - S.123-124.

Onkovich, A. (2013). Media Didactics in Higher Education: OrientedMedia Education // Worldwide Commonalities and Challenges in Information Literacy Research and Practice. 2013. № 307. Springer. Cham. R. 282-287.

Onkovich, A. V. (2012). Медиадидактика // Materiały V Międzynarodowej Konferencji Naukowej «Język rosyjski w przestrzeni językowej i kulturowej Europy i świata: Człowiek. Świadomość. Komunikacja, Warszawa, p. 1013-1018.

Paris Declaration on Media and Information Literacy in theDigital Era [Electronic sourse] / Nordicom. URL:http://www.nordicom.gu.se/en/ clearinghouse/parisdeclaration-media-and-information-literacydigitalera-0 (accessed: 14.11.2019).

Onkovich, G. V. (2018). Novitni termini mediaosviti ta mediadidaktiki // Lingvistika. Lingvokulturologiya. Kroskulturna i mizhkulturna komunikatsiya: problemi. pitannya. rishennya. Dnipro. DNU im. Olesya Gonchara. № 12. Chastina 2. S. 277-291.

Onkovich, A. V. (2015). Internet-didaktika v obuchenii russkomuyazyku kak inostrannomu // Russkiy yazyk i literatura v prostranstve mirovoy kultury : mat-ly XIII Kongressa MAPRYaL. Granada. Ispaniya. 1320 sent. g. SPb.: MAPRYaL. 2015. T. 10. S.788-793.

Onkovich, G.V. (2020). Rozvitok mediadidaktiki vishchoï shkoli: ukraïnskiy dosvid // Obriï drukarstva. 2020. - № 1(8). - S. 130-150.

Onkovych, H. \& Onkovych, A. (2020). Media Didactics as a way to comprehend professionally-oriented terminological systems $\backslash \backslash$ International Scientific-Pedagogical Organization of Philologists " WESTEAST" (ISPOP). Scientific Journal "WEST-EAST:. Vol. 3, N1 (March, 2020). pp. 38-46. doi: https://doi.org/10.33739/2587-5434-2020-3-1-38-46

Onkovich, A., Onkovich, G., Lyalina, O. (2020). Vikididaktika: tematichni vikiuroki - shlyakh do novoï osviti // Novi tekhnologiï navchannya: zbirnik naukovikh prats. DNU «Institut modernizatsiï zmistu osviti». Kiïv. 2020. Vip. 94.338 s. 244 - S.244-252.

Onkovich, G.V.. Bogolyubova M.M. Nove v mediaosviti: bibliotechna blogodidaktika // Suchasni aspekti modernizatsiï nauki v Ukraïni: stan. problemi. tendentsiï rozvitku: materiali II Mizhnarodnoï naukovo- 
praktichnoï konferentsiï. m. Kiïv; Turechchina. 07 zhovtnya 2020 r. / za red. C.O. Romanenka. I.V. Zhukovoï. Kiïv; Turechchina:: FOP KANDIBA T.P.. 2020. 222 s. - S.196 - 199.

Onkovich, G.V., Onkovich, A.D. (2020). Muralodidaktika yak mediaosvitnya tekhnologiya // PR i SMI v Kazakhstane: sbornik nauchnykh trudov. - ?aza?standa?y PR zh?ne BA?: ?ylymi e?bekter zhina?y / sost. i gl. red. L.S. Akhmetova. - Vyp. 19. - Almaty: universiteti. - s. ISBN 978-601-04-4546-8. S.114-124.

Onkovich, G.V., Adamia, Z.K., Onkovich, A.D., Bogolyubova, M.M., Lyalina, O.O. (2020). Nove v mediaosviti: vebinarodidaktika // Suchasni aspekti nauki: II-iy tom kolektivnoï monografiï / za red. C.O. Romanenka. I.V. Zhukovoï. Kiïv; Bratislava: FOP KANDIBA T.P. 223 s.- S.172-189.

Onkovich G.V. Knigospalakh-didaktika. - Rezhim dostupa: https:// www. facebook. com/profile.php?id=100008349217380\& fref $=$ nf

Onkovych, H. (2017). Knyhospalah (flashbook) didactics as media education technology (Knigospalakh(flashbook) didaktika yak mediaosvitnya tekhnologiya) // Aktualni doslidzhennya v sotsialniy sferi : materiali vosmoï mizhnarodnoï naukovo-praktichnoï konferentsiï (m. Odesa. 17 travnya 2017 r.) / gol. red. V. V. Korneshchuk. - Odesa: FOP Bondarenko M.O.. 2017. - 332 s. - S. 309 - 310.

Mikolaïvska oblasna universalna naukova biblioteka // Ukraïnska bibliotechna entsiklopediya entsiklopediya http://ube.nlu.org.ua/article/\%D0\%9C\%D0\%B8\%D0\%BA\%D0\%BE\%D0\%BB $\%$ D0 $\%$ B0 $\%$ D $1 \% 97 \% \mathrm{D}$ 0\%B2\%D1\%81\%D1\%8C\%D0\%BA\%D0\%B0\%20\%D0\%BE\%D0\%B1\%D0\%BB\%D0\%B0\%D1\%81 \%D0\%BD $\%$ D0\%B0\% $20 \% \mathrm{D} 1 \% 83 \% \mathrm{D} 0$

Onkovych, A., Onkovych, G. (2017). "Flashbook" Didactics as a Form of Book Promotion // The Fifth European Conference on Information Literacy (ECIL)/ September 18th-21st. Saint-Malo. France. Abstracts. Publisher: Information Literacy Association (InLitAs) / http://ecil2017.ilconf.org/wpcontent/uploads/sites/6/2017/09/ECIL-2017-Book-of-abstracts.pdf/ - P.206

Globa, T. (2018). Knigospalakh ta kra€znavcha lokatsiya: mediaosvitni tekhnologiï v roboti bibliotek m. Dnipro // https://www.libr.dp.ua/site-dnipro/?idm=\&idp=904 Globa. T. I. Knigospalakh ta kra€znavcha lokatsiya: mediaosvitni tekhnologiï v roboti bibliotek m. Dnipro [Elektronnyy resurs] : sbornik statey / - Mogilev : Mogilev. institut MVD. S. 48?54. // https:/www.libr.dp.ua/sitednipro/?idm=\&idp=904. Data obrashcheniya 26.09.2020.

\section{For citation:}

Oncovich, A. \& Agarkova, V Bogolyubova, M. (2020) Library blogodidactics

// International Scientific-Pedagogical Organization of Philologists "WEST-EAST" (ISPOP). Scientific Journal "WEST-EAST". Vol. 3, N1 (October, 2020). pp. 39-48. https://doi.org/10.33739/2587-5434-2020-3$39-48$

\section{Для цитирования:}

Онкович, А., Агаркова, В., Боголюбова, М. (2020) Библиотечная блогодидактика // International Scientific-Pedagogical Organization of Philologists "WEST-EAST" (ISPOP). Scientific Journal "WEST-EAST". Vol.3, N1 (October, 2020). c. 39-48. https://doi.org/10.33739/2587-5434-2020-3$39-48$

\section{Information about the authors:}

Anna Onkovych - Doctor of Pedagogical Sciences, Professor of the Department of Ukrainian and Latin Languages, Kyiv Medical University, Kyiv, Ukraine email: onkan@ukr.net 
Viktoria Agarkova - Director of Nikolaev Regional Universal Scientific Library, Mykolaiv, Ukraine

Marina Bogolyubova - Senior Lecturer, Department of Ukrainian and Latin Languages, Kiev Medical University, Kyiv, Ukraine

email: m.boholiubova@kmu.edu.ua

\section{Сведения об авторах:}

Онкович Анна Владимировна - доктор педагогических наук, профессор кафедры украинского и латинского языков, Киевский медицинский университет, Киев, Украина email: onkan@ukr.net

Агаркова Виктория Викторовна - директор Николаевской областной универсальной научной библиотеки, Николаев, Украина

Боголюбова Марина Михайловна - старший преподаватель кафедры украинского и латинского языков, Киевский медицинский университет, Киев, Украина

e-mail: m.boholiubova@kmu.edu.ua

Manuscript received: 15/08/2020

Accepted for publication: $14 / 09 / 2020$

Рукопись получена: 15/08/2020

Принята к печати: 14/09/2020

\section{International Scientific-Pedagogical Organization of Philologists "West-East" ISPOP \\ SCIENTIFIC JOURNAL "WEST-EAST" \\ ISSN (print) - 2587-5434 ISSN (online) - 2587-5523}

